\title{
The Impact of Fiscal Policy Convergence on Business Cycle Synchronization between Croatia and Eurozone Countries - Panel Analysis
}

\author{
Mario Pečarić ${ }^{1}$ and Ante Tolj ${ }^{1, *}$ \\ ${ }^{1}$ Faculty of Economics, University of Split, Cvite Fiskovića 5, 21000 Split, Croatia \\ E-mail: \{mpecaric@efst.hr,ante.tolj1306@gmail.com\}
}

\begin{abstract}
This paper analyzes how fiscal policy convergence impacts the business cycle synchronization between Croatia and eurozone countries and consequently indirectly affects the costs of monetary integration using panel data analysis. The main aim of the paper is to create a methodological framework for an empirical model based on critical examination of previous research.

In the empirical model the dependent variable is business cycle synchronization, and the main independent variable is fiscal policy convergence. The problem of simultaneity (reverse causality) between dependent and independent variable is solved by using cyclically adjusted budgetary balance as indicator of discretionary fiscal policy. For control variables in the model we applied determinants of business cycle synchronization often used in this kind of research - financial integration, trade integration and sectoral structure similarity.

Parameter estimation is performed using the fixed effects panel model. Our dataset involves Croatia and the eurozone countries and includes bilateral observations from 2001 to 2016. Unlike similar research which performed mostly cross-sectional analysis, this paper includes the time dimension and puts Croatia in the focus of research which has not been done before. Also, the paper contributes to research methodologically by estimating business cycles using the production function method and by measuring business cycle synchronization by using CerqueiraMartins index. The results confirm that business cycle synchronization is positively influenced by fiscal policy convergence which indicates the necessity to comply with the rules proposed by the Stability and growth pact. It is also suggested that small open economies in process of accession, which is the case of Croatia, need to employ anticyclical discretionary fiscal policy.
\end{abstract}

Keywords: fiscal policy convergence, business cycle synchronization, panel analysis, monetary integration

Received: September 30, 2018; accepted: October 21, 2018; available online: December 13, 2018

DOI: $10.17535 /$ crorr. 2018.0022

\section{Introduction}

Although the Optimal Currency Area Theory (OCA) emphasizes the importance of fiscal policy convergence and business cycle synchronization as a meta criterion of monetary integration, there is no clear theoretical framework that connects them [10]. Countries may be subject to asymmetric shocks, and in addition, common shocks (e.g. changes in oil prices or interest rates) may have asymmetric effects due to different propagation mechanisms. If these shocks can be partially offset with discretionary fiscal policy or automatic fiscal stabilizers, fiscal divergence is associated with greater degree of business cycle synchronization. On the

\footnotetext{
* Corresponding author.
} 
one hand if fiscal policy divergence is a response to asymmetric shocks it has a positive impact on business cycle synchronization. On the other hand, fiscal policy may also be the source of business cycles (shocks) by generating large demand side effects. In that case, divergence of fiscal policies has a negative impact on business cycle synchronization [10]. Thus, to the extent to which fiscal policy shocks are the source of business cycles, fiscal policy divergence can be expected to reduce business cycle synchronization [9]. That negative impact complicates the conduction of common monetary policy and increases macroeconomic costs of adopting common currency, which is particularly significant for Croatia.

Fidrmuc and Korhonen [14] argue that the degree of business cycle synchronization should be an important criterion for joining the monetary union and that it is being applied consistently to the processes of adopting euro in the new EU member countries and in the countries with intense trade and economic relations with EU countries. High level of business cycle synchronization between Croatia and eurozone countries means that a single monetary policy will be a good substitute for the current Croatian monetary policy, which implies lower costs of renouncing its own monetary policy, i.e. lower costs of monetary integration for Croatia.

Conducting effective and coordinated fiscal policy is particularly important for small, open and highly euroised economies such as Croatia with an exchange rate anchor, due to limited possibilities of monetary policy which is focused on price stability and its procyclicality. Apart from its advantages, adoption of euro also imposes potential costs to Croatia. These would be particularly high if the mechanisms of insurance and coordination of decentralized fiscal policies were not able to mitigate common and country-specific shocks. Implementation of fiscal policy at the national level in the EU is determined by the Maastricht criteria and by the Stability and Growth Pact. These define the rules of conduct for the countries that should prevent chronic budget deficit and high public debt which have negative effects on other countries too. The Stability and Growth Pact further stipulates that the medium-term budgetary positions of the EU countries must be balanced or in surplus, implicitly assuming the convergence of countries fiscal policies. Fiscal convergence means closing the fiscal gap with other countries [10].

The important role of fiscal policy as a shock absorption mechanism is achievable only if it is counter-cyclical. In this context, discretionary fiscal policy should be neutral (acyclic) during a business cycle, and should smooth out the business cycle fluctuations by anti-cyclic action of automatic fiscal stabilizers. However, countries discretionary fiscal policies are often procyclical. Dulien [12] argues that in the period from 1991 to 2006, out of all the EMU countries, only Austria and Finland used fiscal policy to systematically stabilize cyclical fluctuations. Discretionary fiscal policy in the EMU countries counteracted the effects of automatic stabilizers and thus prevented the stabilization role of the overall fiscal policy [12]. Research yields similar results for Croatia too. Deskar-Škrbić et al. [11] point out that Croatia's fiscal policy in the period from 2008 to 2012 was not adequate and that its stabilization potential was not fully utilized. Also, in the period from 2003 to 2016, Croatia's discretionary fiscal policy was largely procyclical.

Numerous empirical studies have confirmed that fiscal policy convergence positively impacts business cycle synchronization, [2], [15], [23]. Similarly, Artis, Fidrmuc and Scharler [4] analyze the determinants of business cycle synchronization of OECD countries and the new member states (the Czech Republic, Hungary, Poland, Slovakia and Slovenia). They confirm that divergent fiscal policies reduce the business cycle synchronization and conclude that Maastricht convergence criteria should allow further synchronization of business cycles due to the greater convergence of fiscal policies. Akin [1] examines the impact of similarity of macroeconomic policies in synchronizing business cycles within 51 countries (out of which 27 growing markets). He confirms that differences in public consumption positively impact business cycle synchronization (noticing a particularly strong effect in the period from 1990 to 2008) and that anticyclical fiscal policy can mitigate the effects of country-specific shocks. Finally, he concludes that faster and stronger shock transmission between countries requires international policy coordination. Bower and Gullemineau [7] analyze the potential determinants of the business cycle synchronization in the context of 
Croatia and eurozone countries - panel analysis

European Monetary Integration of 12 eurozone countries. They argue that similar fiscal policies increase business cycle synchronization but point out the possibility of reversed causality because the same phases of the business cycle induce similar responses to their fiscal policies. Antonakakis and Tondl [3] analyze the impact of market integration and economic policy coordination on business cycle synchronization within 27 EU member states. They find out that the countries' weak fiscal discipline is a major obstacle to business cycle synchronization and that the EU should strictly apply the Stability and Growth Pact. In contrast, Clark and Van Wincoop [9] find no link between fiscal policy coordination and business cycle synchronization between 14 EU countries. Lukmanova and Tondl [29] show that differences in fiscal policies produce immediate de-synchronization of business cycles in the eurozone. They argue that stronger common economic governance is needed for functioning and survival of the Eurozone.

The aim of this paper is to create a methodological framework for an empirical model, based on the critical analysis of previous research. The paper is methodological in nature. Its methodological contribution is manifested in estimating business cycles using the production function method; using the CerqueiraMartins [8] correlation index for business cycle synchronization measurement and using the panel analysis with Croatia as a benchmark country. The fixed effects model that is used analyzes how fiscal policy convergence impacts business cycle synchronization between Croatia and eurozone countries and indirectly affects the cost of monetary integration.

The dependent variable is business cycle synchronization, and the main independent variable is fiscal policy convergence. The problem of simultaneity (reverse causality) between dependent and independent variable is solved by using cyclically adjusted budgetary balance as indicator of fiscal policy, that represents discretionary fiscal policy. For control variables in the model we applied determinants of business cycle synchronization often used in this kind of research - financial integration, trade integration and sectoral structure similarity. Our dataset includes Croatia and 19 eurozone countries and the time span includes the period from 2001 to 2016. Unlike similar research which mostly used cross-sectional analysis (averaging variables over a given time span), this paper includes time dimension (time variability) and puts Croatia in the focus of research which has not been done before. Spatial dimension includes 19 bilateral observations (Croatia with every eurozone country).

In the second part of the paper we critically analyzed the methodological frameworks present in previous research of the relationship between fiscal policy convergence and business cycle synchronization. The improved methodological framework is presented in the second part while the econometric panel model and the research results based on this framework are discussed in the third section of the paper. Finally, the paper ends with the concluding remarks.

\section{Methodological framework}

\subsection{Estimation of the business cycles and measures of the business cycle synchronization}

Previous research has applied a variety of methods for estimating business cycles ${ }^{1}$ and a range of measures for business cycle synchronization. Darvas, Rose and Szapary [10] use three indicators of real economic activity - real GDP, unemployment rate and index of industrial production. They estimate business cycles using Hodrick-Prescott [20] filter (HP) and measure business cycle synchronization by Pearson's [30]

${ }^{1}$ Business cycles can not be directly measured but need to be estimated. Business cycle estimation consists of two basic steps: choosing a real economic activity indicator and selecting a filter by which the cyclic component will be isolated. 
correlation coefficient. Alimi [2], Antonakakis and Tondl [3] and Fonseca, Patureau and Sopraseuth [15] apply the same approach to estimating business cycles and measuring business cycle synchronization. Inklaar, Jong-A-Pin and De Haan [23] use two indicators of real economic activity: real quarterly GDP and industrial production index which is interesting because it is available for longer period of time on monthly frequency. They estimate business cycles using Baxter-King filter. The same filter is used by Bower and Gullemineau [7] and Akin [1], where Akin [1] also uses Fisher z-transformation for achieving normality of distribution. Business cycle synchronization is again measured by Pearson's coefficient of correlation. Unlike them, Artis, Fidrmuc and Scharler [4] estimate business cycles using fourth differences of quarterly real GDP deseasonalized by X12 ARIMA procedure. They measure business cycle synchronization by contemporaneous correlation for which they argue it has direct implications for potential cost of monetary integration. They use Fisher transformation to avoid the limit of the dependent variable in the interval [1,1]. Lukmanova and Tondl [29] measure business cycle synchronization by dynamic conditional correlation method that belongs to the class of multi-variate GARCH model.

Most of the above-mentioned research estimate business cycles by isolating cyclical component using HP filter which belongs to the high-band filter group. HP filter eliminates fluctuations with a frequency of more than 32 quarters and puts them in trend. The separation of time series on the trend and cyclic component is done by solving the problem of minimization:

$$
\min _{\tau}\left\{\sum_{t=1}^{T}\left(y_{t}-\tau_{t}\right)^{2}+\lambda \sum_{t=2}^{T-1}\left[\left(\tau_{t+1}-\tau_{t}\right)-\left(\tau_{t}-\tau_{t-1}\right)\right]^{2}\right\}
$$

where $y$ represents a time series, $\tau$ represents a trend and $\lambda$ represents the multiplier. The solution to minimizing the problem involves selecting such a trend series $\{\tau\}_{t=1}^{T}$ that minimizes the sum of squares mentioned above. The multiplier $\lambda$ represents the cost of including fluctuations into the trend, whereby the higher value of the parameter exercises a stronger smoothing effect on the trend component. The recommended values for the smoothing parameter $\lambda$ are: $\lambda=14400$ for the time series on the monthly frequency; $\lambda=1600$ for quarterly time series; and $\lambda=100$ for time series on annual frequency. Although it is often used in similar research because it is easy to use, its application includes several problems. Akin [1] points out that the criticisms of using HP filters most often relate to the arbitrary selection of smoothing parameters $\lambda$ that depends on user's preferences. Also, in the case of application to the difference-stationary series it artificially amplifies business cycle frequency and induces a spurious cycle. Further, in the event of persistent shocks, the HP filter generates a shift in the trend that does not really exist, thereby smoothing out the effects of sudden structural breaks in previous and future periods. Jovičić [24] points out that HP is a two-sided symmetric filter and that therefore estimates at the end of the sample may change considerably with the arrival of new observations (end-of-sample problems). Additionaly, the HP filter is a fully statistical approach to assessing potential GDP that is not directly related to economic theory.

In this paper, business cycles are estimated by using the output gaps that are calculated according to the production function method. Unlike the statistical assumptions used in calculating the trend of time series using univariate filters, the production function method uses assumptions based on economic theory. The production function method implicitly defines potential output as a level of production that can be achieved over a longer period without excessive exploitation of existing production capacities. It assumes Cobb-Douglas's form of production function:

$$
Y_{t}=T F P_{t} * L_{t}^{\beta} * K_{t}^{(1-\beta)}
$$

where $Y_{t}$ denotes the gross domestic product, $T F P_{t}$ total factor productivity, $L_{t}$ the amount of labor used, $K_{\mathrm{t}}$ the amount of capital, and $\boldsymbol{B}$ the share of the factor in the gross domestic product. The production function specification is based on the assumption of constant returns to scale $(\beta=0.65)$. The calculation of the GDP gap requires an estimate of potential GDP, which consists of estimates of employment trend and trend in total factor productivity. Total factor productivity trend was estimated from Solowl's residuals using the bivariate Kalman filter [19]. Estimate of employment trend is defined in the following way: 
where POP stands for the total working-age population, PART stands for trend in participation rate, $\mathrm{H}$ stands for trend of average working hours per worker, and NAWRU stands for structural unemployment.

Finally, the output gap $\left(Y_{\text {gap }}\right)$ is calculated according to the formula:

$$
Y_{\text {gap }}=\left(\frac{Y_{\text {act }}}{Y_{\text {pot }}}-1\right)
$$

where $Y_{p o t}$ represents potential output, and $Y_{a c t}$ is actual output.

As one of the greatest advantages of this method Jovičić [24] points out the possibility of dividing the growth of potential GDP into labor, capital and total factor productivity gains. The method of production function is often used in practice. It is applied by HNB, the European Central Bank and the European Commission [24]. In previous research business cycle synchronization is most often measured by Pearson's correlation coefficient. Although it is constructed from a time series, this is a static indicator because it does not have a time dimension. Kamenduliene and Lydeka [26] point out that the Pearson's correlation coefficient shows relative synchronization, but is unable to show the evolution of business cycle synchronization, i.e. the dynamics of change. Static indicators smooth the change over time - the longer the period, the greater the degree of smoothing. Antonakakis and Tondl [2] include the time component by using rolling windows, but this approach results in variables that are autocorrelated and therefore difficult to manage in econometric analysis.

Calculating the Pearsons correlation coefficient requires a longer time series2 that implies smoothing variables in the model, i.e. loss of their time dynamics. In this way sample partially or completely loses the structure of the panel. To overcome this problem, this paper uses the dynamic correlation coefficient modeled on Cerqueira and Martins [8].

The Cerquiera-Martins correlation index is calculated according to the formula:

$$
\rho_{i j t}=1-\frac{1}{2}\left(\frac{\left(d_{j t}-\bar{d}_{j}\right)}{\sqrt{\frac{1}{T} \sum_{t=1}^{T}\left(d_{j t}-\bar{d}_{j}\right)^{2}}}-\frac{\left(d_{i t}-\bar{d}_{i}\right)}{\sqrt{\frac{1}{T} \sum_{t=1}^{T}\left(d_{i t}-\bar{d}_{i}\right)^{2}}}\right)^{2}
$$

where $d_{i t}$ denotes the GDP growth rate of the country $i$ in period $t$, and $d_{i}$ average GDP growth rate of the country $i$ in the observed period.

The use of the Cerquiera-Martins correlation index has advantages over static indicators because: (i) there is no need to set the time frame, (ii) no loss of observations, and (iii) it does not show the so-called "ghost features" [8]. The use of this indicator, apart from introducing the dynamic component in the analysis, allows maximum sample utilization (number of observations), which is desirable due to the specificity of the analysis involving a relatively small number of observations compared to other studies.

\subsection{Estimation of the model parameters}

In previous research the estimation of model parameters has been carried out by various methods. Bower and Gullemineau [7] identify the key determinants of business cycle synchronization by applying extreme bounds analysis. Darvas, Rose and Szapary [10] and Inklaar, Jong-A-Pin and De Haan [23] model parameters are estimated by OLS and instrument variables (IV). Additionaly, Inklaar, Jong-A-Pin and De Haan [23] use the three-stage least squares method (3SLS). In contrast, Lukmanova and Tondl [29] use a system of simultaneous equations based on Imbs [22]. Dependent variables are explained by 5 endogenous variables modeled separately within the system, enabling them to detect various indirect effects. The variables are transformed in the form of 5-period overlapping moving averages by taking the average of the

${ }^{2}$ In the case of the use of quarterly GDP, 20 observations, i.e. a time period of 5 years are most commonly taken. 
two previous periods, the current period and the two future periods. Thus, they lose part of the observations and partially smooth the fluctuations of the variables. Akin [1] model parameters are estimated by the GMM-IV method, whereby the endogenous variables and the need for their instrumentalization are identified by Durbin-Wu-Hausman's test. Given that the GMM-IV method allows an estimate of the overall effects of the observed variables on the business cycle synchronization, the direct and indirect effects of economic links are identified by using the 3SLS method in the model of simultaneous equations as modeled in Imbs [22]. Artis, Fidrmuc, and Scharler [4] estimate the model parameters using instrumental variables for financial and trade integration, while not using instrumentalization for fiscal policy convergence.

Antonakakis and Tondl [3] solved the problem of simultaneity/endogeneity of explanatory variables by using the system of simultaneous equations as in Imbs [22]. In the auxiliary equation for fiscal policy coordination, the differences in budget deficits have been explained by differences in degree of development, degree of business cycle synchronization and two exogenous variables - differences in government efficiency and long-term interest rate differences. In contrast, Fonseca, Patureau and Sopraseuth [15] reduced the problem of endogeneity by using instrumental variables, whereby the convergence of fiscal policies is instrumentalized by the average absolute difference of non-wage consumptions relative to GDP, the average absolute difference between government investments relative to GDP and the average absolute difference in direct business taxes relative to GDP.

Estimation of the model parameters in this paper is performed by a fixed effects model that has the following formulation:

$$
Y_{i t}=\alpha+\beta_{1} X^{\prime}{ }_{i t}+\mu_{i}+v_{i t} \quad \mathrm{i}=1, \ldots, \mathrm{N} ; \mathrm{t}=1, \ldots, \mathrm{T}
$$

where $Y$ denotes dependent variable, $\alpha$ scalar, $\beta_{1} \mathrm{~K} \times 1, X_{i t}^{\prime}$ it-th observation on explanatory variables, $\mu_{i}$ unobservable individual-specific effect, $v_{i t}$ remainder disturbance, i cross-sectional units (country pairs) and $\mathrm{t}$ time. Unobservable individual-specific effect is time-invariant, and the remainder disturbance varies with individuals and time and is assumed to be independent and identically distributed. Explanatory variables are assumed independent of the remainder disutrbance for all $i$ and t. Fixed effects model is estimated by least squares dummy variable (LSDV) and within effect estimation methods.

The fixed effects model controls for the hard-to-measure time-invariant variables with time invariant effects, which reduces the problem of endogeneity resulting from the omitted variables. Numerous studies confirm that time-invariant variables have a significant impact on business cycle synchronization (distance, common language, institutional and structural characteristics, cultural and political similarity). Previous research analyse all possible pairs of countries from the sample. By contrast, in this paper, as modeled on Garcia-Herrero and Ruiz $[17]^{3}$, Croatia is used as a benchmark country which means that the pairs of countries that do not include Croatia are excluded from the analysis. Garcia-Herrero and Ruiz [17] suggest that using small open economies as benchmark countries reduces the problem of omitted variables often occurring in similar research. Additionally, this also puts focus on Croatia and helps make important policy implications and to analyze the costs related to the introduction of the euro. Unlike Garcia-Herrero and Ruiz [17] who use cross-sectional regression and thus neglect the time dimension, this paper uses fixed effects model to provide time dynamics of the observed variables.

${ }^{3}$ Garcia-Herrero and Ruiz [17] used Spain as a benchmark country. 


\section{Model and results}

Parameter estimation was performed by using the fixed effects models in $\mathrm{Hsu}, \mathrm{Wu}$ and Yau $[21]^{4}$. Business cycle synchronization $\left(\rho_{i j t}\right)$ is explained by four variables: fiscal policy convergence $\left(K F P_{i j t}\right)$, trade integration $\left(T I_{i j t}\right)$, financial integration $\left(F I_{i j t}\right)$ and similarity of economic structures $\left(S E S_{i j t}\right)$ :

$$
\rho_{i j t}=\alpha_{0}+\alpha_{1} K F P_{i j t}+\alpha_{2} T I_{i j t}+\alpha_{3} F I_{i j t}+\alpha_{4} S E S_{i j t}+\varepsilon_{i j t}
$$

where ijt stands for the index of pairs of countries $(i, j)$ in period $t$, and $\varepsilon$ is the disturbance term.

The sample includes Croatia and 19 eurozone countries ${ }^{5}$. The time spans the period from 2001 to 2016. Given the nature of the research which analyses Croatia with the eurozone countries, the spatial dimension includes 19 bilateral observations (Croatia with each of the countries of the eurozone) and together with the time dimension of 16 observations gives a total of $n=19 * 16=304$ observations. Statistical analysis is performed using data analysis software Stata.

The results of the t-test for the dependent variable confirm that there is no difference between the arithmetic mean in the pre-crisis period (2001-2008) and the post-crisis period (2009-2016), which allows the econometric analysis to be performed on the whole sample. The correlation matrix confirms that, apart from the $T I_{i j t}$ and $F I_{i j t}$ variables that are bordering acceptable correlation, there is no significant correlation between independent variables. An additional variance inflation factor (VIF) analysis confirms that there is no problem of multicollinearity between the independent variables. The results of the modified Wald test indicate the existence of heteroskedasticity that was removed by using the Eicker-Huber-White estimator. The results of the Wooldridge autocorrelation test confirm that there is a residual autocorrelation which is controlled by using the lagged dependent variable. The decision to apply the fixed model and not the random effects model was based on the results of the Hausman's test which confirmed its suitability.

Business cycle synchronization is measured by the Cerqueira-Martins [8] correlation index, but unlike in their paper, this study estimates business cycles by using output gap. The data for the output gap is taken from the annual macro-economic database of the European Commission's Directorate General for Economic and Financial Affairs (AMECO).

Trade integration is defined as in Frankel and Rose [17]:

$$
\mathrm{TI}_{\mathrm{ijt}}=\frac{x_{i j t}+m_{i j t}}{Y_{i t}+Y_{j t}}
$$

where $x_{i j t}$ represents the export of the country $i$ to the country $j$ in the period $t, m_{i j t}$ the import of the country $i$ from the country $j$ in the period $t$, and $Y_{i t}$ nominal GDP of the country $i$ in the period $t$. The data for import and export are taken from the UN Comtrade database. The expected sign of a coefficient $\alpha_{2}$ is ambiguous. On the one hand, trade integration generates demand-side effects (Keynes multiplier), i.e. it causes the stronger spillover of demand shocks from one country to another, and positively impacts business cycle synchronization. On the other hand, according to Heckscher-Ohlin's theory, greater trade integration induces specialization of production according to the country's comparative advantages. Countries become more vulnerable to industry-specific shocks, which causes de-synchronization of business cycles.

Financial integration is measured based on the following formula:

$$
F I_{i j t}=\frac{f i_{i j t}+f o_{i j t}}{Y_{i t}+Y_{j t}}
$$

\footnotetext{
${ }^{4}$ The authors point out the potential endogeneity problem and possible indirect effects of the variables. Therefore, they additionally use the error-component three-stage least squares (EC3SLS) as a parameter estimation method. In this paper we focus on the total effect of the variables so the parameter estimation is done only by using a fixed effects model.

${ }^{5}$ Austria, Belgium, Cyprus, Estonia, Finland, France, Greece, Ireland, Italy, Latvia, Lithuania, Luxembourg, Netherlands, Germany, Malta, Portugal, Slovakia, Slovenia and Spain.
} 
where fijit represents the cumulative inflow of foreign direct investments from the country $i$ to the country $j$ in the period $t$, and $f_{i j t}$ the cumulative outflow of foreign direct investments from the country $i$ to the country $j$ in the period $t$. The data for cumulative inflow and outflow of foreign direct investments are taken from the Wien Institute for International Economic Studies database (WIIW). The expected sign of coefficient $\alpha_{3}$ is ambiguous. According to the International real business cycles theory highly mobile capital moves from one country to another seeking the highest return [5]. Thus, it amplifies the total factor productivity shocks and decreases business cycle synchronization. On the other hand, financial integration increases business cycle synchronization through the mechanism of international financial multipliers [28].

The similarity of economic structures is measured as in Krugman [27]:

$$
S E S_{i j t}=\sum_{n=1}^{N}\left|s_{n i t}-s_{n j t}\right|
$$

where $s_{n i t}$ represents the share of the sector $n$ of the country $i$ in the gross added value of the country $i$ in period $t$. The data for the sectoral gross added value is taken from the Eurostat database. The expected sign of coefficient $\alpha_{4}$ is negative. A more diverse composition of sectoral structures implies greater sensitivity to the occurrence of industry-specific shocks and different reactions of economies to the occurrence of common shocks which negatively impacts business cycle synchronization.

Fiscal policy convergence is measured as in [4] and [23]:

$$
K F P_{i j t}=-\left|d_{i t}-d_{j t}\right|
$$

where $d_{i t}$ represents the structural balance of the country $i$ in the period $t$. The data on structural budget balances are taken from the International Monetary Fund (IMF). Darvas, Rose and Szapary [10], Bower and Gullemineau [7], Antonakakis and Tondl [3] and Alimi [2] measure fiscal policy convergence by the absolute differences between the total budget balances in GDP. By contrast, Fonseca, Patureau and Sopraseuth [15] and Lukmanova and Tondl [29] measure fiscal policy convergence by the absolute difference of the primary budget balances in GDP. Akin [1] measures similarity of fiscal policies by the average absolute difference between public spending in GDP. By using the structural fiscal balance as fiscal policy indicator he removes the problem of simultaneity, i.e. eliminates the possible impact of the business cycle on the fiscal policy.

The expected sign of the coefficient $\alpha_{1}$ is ambiguous. On the one hand, if fiscal policies have a stabilizing role, fiscal convergence negatively impacts business cycle synchronization, i.e. the sign of the coefficient $\alpha_{1}$ is negative. On the other hand, if fiscal policy shocks are the source of the business cycles, fiscal policy convergence leads to greater business cycle synchronization and the sign of the $\alpha_{1}$ coefficient is positive. The results of the fixed effects model are shown in table 1. 
The impact of fiscal policy convergence on business cycle synchronization between

Croatia and eurozone countries - panel analysis

\begin{tabular}{|c|c|c|c|c|c|}
\hline & $(1)$ & $(2)$ & $(3)$ & $(4)$ & $(5)$ \\
\hline \multicolumn{6}{|c|}{ Business cycle synchronization $(\rho)$} \\
\hline Fiscal policy convergence $(\alpha 1)$ & $\begin{array}{c}0.088 \\
(0.044)^{*}\end{array}$ & $\begin{array}{c}0.101 \\
(0.044)^{* *}\end{array}$ & $\begin{array}{c}0.037 \\
(0.035)\end{array}$ & $\begin{array}{c}0.098 \\
(0.043)^{* *}\end{array}$ & $\begin{array}{c}0.103 \\
(0.048)^{* *}\end{array}$ \\
\hline Trade integration $(\alpha 2)$ & $\begin{array}{c}0.280 \\
(0.105)^{*} \\
*\end{array}$ & & $\begin{array}{c}0.181 \\
(0.058)^{* *}\end{array}$ & $\begin{array}{c}0.264 \\
(0.106)^{* *}\end{array}$ & $\begin{array}{c}0.252 \\
(0.101)^{* *}\end{array}$ \\
\hline Financial integration $(\alpha 3)$ & $\begin{array}{c}-0.221 \\
(0.105)^{*} \\
*\end{array}$ & $\begin{array}{c}-0.186 \\
(0.653)^{* *}\end{array}$ & & $\begin{array}{c}-0.249 \\
(0.093)^{* *}\end{array}$ & $\begin{array}{c}-0.226 \\
(0.085)^{* *}\end{array}$ \\
\hline Sectoral structure similarity ( $\alpha 4)$ & $\begin{array}{l}-0.773 \\
(0.683) \\
\end{array}$ & $\begin{array}{l}-0.517 \\
(0.686) \\
\end{array}$ & $\begin{array}{l}-0.620 \\
(0.611) \\
\end{array}$ & & $\begin{array}{l}-0.429 \\
(0.657)\end{array}$ \\
\hline Lagged BCS & & $\begin{array}{c}0.170 \\
(0.075)^{* *}\end{array}$ & $\begin{array}{c}0.177 \\
(0.066)^{* *}\end{array}$ & $\begin{array}{c}0.174 \\
(0.076)^{* *}\end{array}$ & $\begin{array}{c}0.163 \\
(0.077)^{* *}\end{array}$ \\
\hline constant & $\begin{array}{c}1.897 \\
(0.999)^{*}\end{array}$ & $\begin{array}{c}0.692 \\
(1.028)\end{array}$ & $\begin{array}{c}2.033 \\
(0.824)^{* *}\end{array}$ & $\begin{array}{c}0.573 \\
(0.231)^{* *}\end{array}$ & $\begin{array}{c}1.217 \\
(0.968)\end{array}$ \\
\hline \multicolumn{6}{|c|}{$\begin{array}{l}\text { Robust standard errors are shown in parentheses; } \\
\qquad * * * \text { Significance at } 5 \%, 10 \%\end{array}$} \\
\hline
\end{tabular}

Table 1. Results of the fixed effects model. Source: Author's calculations.

A positive, statistically significant coefficient $\alpha_{1}$ confirms that the fiscal policy convergence positively impacts the synchronization of the Croatian business cycle with the business cycles of the eurozone countries. Divergent fiscal policies are causing asymmetric shocks, thus reducing the synchronization of Croatian business cycles with the business cycles of the eurozone countries and increasing the costs of Croatian monetary integration. The findings are in line with [2], [3], [4], [7], [10], [15], [23] and [29]. A positive, statistically significant coefficient $\alpha_{2}$ confirms that trade integration positively impacts the synchronization of Croatian business cycle with the business cycles of the eurozone countries. Trade integration generates demand-side effects and increases synchronization of the Croatian business cycles with the business cycles of the eurozone countries. The findings are in line with [3], [6], [13], [16], [18] and [22]. Negative, statistically significant coefficient $\alpha_{3}$ confirms that financial integration negatively impacts the synchronization of the Croatian business cycle with the business cycles of the eurozone countries. Highly mobile capital amplifies the shocks of total factor productivity and causes divergence of the business cycles. In addition, financial integration induces specialization making the countries more vulnerable to industryspecific shocks and causes desynchronization of their business cycles. The negative impact is also confirmed in [3], [8], [17] and [25]. Coefficient $\alpha_{4}$, although with the correct sign, is not statistically significant, which can be explained by the fact that in the observed period there was stronger impact of the common shocks than industry-specific shocks. The results are in accordance with the findings of [6] and [9].

\section{Conclusion}

The methodological contribution of this work is threefold. First, disadvantages of the univariate filters that were often used in previous research was removed by estimating business cycles using the production function method. Second, the problem of neglecting the dynamics of change characterized by Pearson's correlation coefficient often used in previous research was removed by using the Cerqueira-Martins correlation index for measuring business cycle synchronization. Third, applying the fixed effects model and using a small open economy (Croatia) as a benchmark country reduced the problem of omitted variables 
and controlled for the impact of hard-to-measure time-invariant variables that have a significant impact on business cycle synchronization.

The results confirm that fiscal policy convergence synchronizes business cycles between Croatia and the eurozone countries, which implies the need to comply with the rules proposed by the Maastricht criteria and the Stability and Growth Pact in order to lower the macroeconomic costs of Croatian monetary integration. In addition, the important role of fiscal policy as a shock absorption mechanism requires a shift of Croatian discretionary fiscal policy from procyclical to anti-cyclical.

\section{References}

[1] Akın, C. (2012). Multiple determinants of business cycle synchronization. https://papers.ssrn.com/sol3/papers.cfm?abstract_id=1022648 [Accessed 13/06/18].

[2] Alimi, N. (2015). The effect of trade, specialization and financial integration on business cycles synchronization in some mediterranean countries. Asian Economic and Financial eview, 5(1), 110-118.

[3] Antonakakis, N. and Tondl, G. (2014). Does integration and policy coordination promote business cycle synchronization in the EU? Emipirica 41(3), 541-575.

[4] Artis, M., Fidrmuc, J. and Scharler, J. (2008). The transmission of business cycles. Implications for EMU enlargement. Economics of Transition, 16(3), 559-582.

[5] Backus, D., Kehoe, P. and Kydland, F. (1992). International Real Business Cycles. Journal of Political Economy, 100(4), 745-775.

[6] Baxter, M. and Kouparitsas, M. (2005). Determinants of business cycle comovement: a robust analysis. Journal of Monetary Economics, 52, 113-157.

[7] Bower, U. and Guillemineau, C. (2006). Determinants of business cycle synchronisation across euro area countries. European Central Bank, Working Paper Series No. 587.

[8] Cerqueira, P. A. and Martins, R. (2009). Measuring the determinants of business cycle synchronization using a panel approach. Economics Letters, 102(2), 106-108.

[9] Clark, T. E. and Van Wincoop, E. (2001). Borders and business cycles. Journal of international Economics, 55(1), 59-85.

[10] Darvas, Z., Rose, A. and Szapary, G. (2007). Fiscal Divergence and Business Cycle Synchronization: Irresponsibility is Idiosyncratic. In Frankel J. and Pissarides, C. (Eds.), NBER International Seminar on Macroeconomics 2005 (pp. 261-298). Cambridge: MIT Press.

[11] Deskar-Škrbić, M., Šmović, H. and Ćorić, T. (2014). The effects of fiscal policy in a small open transition economy: the case of Croatia. Acta Oeconomica, 64 (1), 133-152.

[12] Dullien, S. (2007). Improving Economic Stability in Europe: What the Euro Area can learn from the United States Unemployment Insurance. German Institute for Interntional and Security Affairs. Working paper FG 1, SWP Berlin.

[13] Duran, H. and Ferreira-Lopes, A. (2017). Determinants of co-movement and of lead and Lag behavior of business cycles in the Eurozone. International Review of Applied Economics, 31(2), 255-282.

[14] Fidrmuc, J. and Korhonen, I. (2006). Meta-Analysis of Business Cycle Correlations between the euro area and CEEC's. Journal of Comparative Economics, 34, 518-537.

[15] Fonseca, R., Patureau, L. and Sopraseuth, T. (2010). Business Cycle Comovement and Labor Market Institutions: An Empirical Investigation. Review of International Economics, 18(5), 865-881.

[16] Frankel, J. and Rose, A. (1998). The Endogeneity of the Optimum Currency Area Criteria. The Economic Journal, 108, 1009-1025.

[17] Garcia Herrero, A., and Ruiz, J. M. (2008). Do Trade and Financial Links Foster Business Cycle Synchronization in a Small Open Economy. Moneda y Credito, 226(1), 187-226. 
Croatia and eurozone countries - panel analysis

[18] Gouveia, S. and Correia, L. (2013). Trade Integration and Business Cycle Synchronization in the Euro Area: The Case of Southern European Countries. Journal of Economic Integration, 28(1), 85-107.

[19] Havik, K., Mc Morrow, K., Orlandi, F., Planas, C., Raciborski, R., Roeger, W., Rossi, A., ThumThysen, A. and Vandermeulen, V. (2014). The Production Function Methodology for Calculating Potential Growth Rates \& Output Gaps.

http://ec.europa.eu/economy_finance/publications/economic_paper/2014/pdf/ecp535_en.pdf [Accessed 13/06/18].

[20] Hodrick, R. J. and Prescott, E. C. (1997). Postwar U.S. Business Cycles: An Empirical Investigation. Journal of Money Credit and Banking, 29(1), 1-16.

[21] Hsu, C., Wu J. and Yau, R. (2011). Foreign direct investment and business cycle co-movements: The panel data evidence. Journal of Macroeconomics 33, 770-783.

[22] Imbs, J. (2004). Trade, finance, specialization and synchronization. The Review of Economics and Statistics, 86(3), 723-734.

[23] Inklaar, R., Jong-A-Pin, R., De Haan, J. (2008). Trade and business cycle synchronization in OECD countries - A re-examination. European Economic Review, 52, 646-666.

[24] Jovičić, G. (2017). Procjena potencijalnog rasta i jaza BDP-a u Hrvatskoj. http://www.hnb.hr/documents/20182/2112241/p-038.pdf/87044a86-7326-406c-95b2-56b258ddf706 [Accessed 13/06/18].

[25] Kalemli-Ozcan, S. Papaioannou, E., Peydro, J. (2013). Financial Regulation, Financial Globalization and the Synchronization of Economic Activity. The journal of finance, 68(3), 1179-1228.

[26] Kamanduliene, A. and Lydeka, Z. (2011). Methodological aspects of business cycle synchronization research. https://ejournals.vdu.lt/index.php/applied-economics/article/download/370/308 [Accessed 13/06/18].

[27] Krugman, P. (1991). Geography and Trade. Cambridge, MA: MIT Press.

[28] Krugman, P. (2008). The International Finance Multiplier. https://www.princeton.edu/ pkrugman/finmult.pdf [Accessed 13/06/18].

[29] Lukmanova, E. and Tondl, G. (2017). Macroeconomic imbalances and business cycle synchronization. Why common economic governance is imperative for the Eurozone. Economic Modelling, 62, 130-144.

[30] Pearson, K. (1895). Notes on Regression and Inheritance in the Case of Two Parents. Proceedings of the Royal Society of London, 58, 240-242. 